\title{
Limitations of using a thermal imager for snow pit temperatures
}

\author{
M. Schirmer and B. Jamieson \\ Department of Civil Engineering, University of Calgary, Calgary, Canada \\ Correspondence to: M. Schirmer (michael.w.schirmer@ucalgary.ca)
}

Received: 27 September 2013 - Published in The Cryosphere Discuss.: 29 October 2013

Revised: 7 February 2014 - Accepted: 12 February 2014 - Published: 11 March 2014

\begin{abstract}
Driven by temperature gradients, kinetic snow metamorphism plays an import role in avalanche formation. When gradients based on temperatures measured $10 \mathrm{~cm}$ apart appear to be insufficient for kinetic metamorphism, faceting close to a crust can be observed. Recent studies that visualised small-scale $(<10 \mathrm{~cm})$ thermal structures in a profile of snow layers with an infrared (IR) camera produced interesting results. The studies found melt-freeze crusts to be warmer or cooler than the surrounding snow depending on the large-scale gradient direction. However, an important assumption within these studies was that a thermal photo of a freshly exposed snow pit was similar enough to the internal temperature of the snow. In this study, we tested this assumption by recording thermal videos during the exposure of the snow pit wall. In the first minute, the results showed increasing gradients with time, both at melt-freeze crusts and artificial surface structures such as shovel scours. Cutting through a crust with a cutting blade or shovel produced small concavities (holes) even when the objective was to cut a planar surface. Our findings suggest there is a surface structure dependency of the thermal image, which was only observed at times during a strong cooling/warming of the exposed pit wall. We were able to reproduce the hot-crust/coldcrust phenomenon and relate it entirely to surface structure in a temperature-controlled cold laboratory. Concave areas cooled or warmed more slowly compared with convex areas (bumps) when applying temperature differences between snow and air. This can be explained by increased radiative and/or turbulent energy transfer at convex areas. Thermal videos suggest that such processes influence the snow temperature within seconds. Our findings show the limitations of using a thermal camera for measuring pit-wall temperatures, particularly during windy conditions, clear skies and large temperature differences between air and snow. At crusts or other heterogeneities, we were unable to create a sufficiently
\end{abstract}

planar snow pit surface and non-internal gradients appeared at the exposed surface. The immediate adjustment of snow pit temperature as it reacts with the atmosphere complicates the capture of the internal thermal structure of a snowpack with thermal videos. Instead, the shown structural dependency of the IR signal may be used to detect structural changes of snow caused by kinetic metamorphism. The IR signal can also be used to measure near surface temperatures in a homogenous new snow layer.

\section{Introduction}

Faceting as part of the kinetic snow metamorphism contributes to avalanche formation. Faceted crystals close to melt-freeze crusts were also observed in the absence of gradients needed for kinetic metamorphism when measured with thermometers $10 \mathrm{~cm}$ apart (Jamieson, 2006; Smith and Jamieson, 2009). One explanation for the development of facets during the absence of gradients may be found in the coarse measuring resolution. Thus, recent studies were promising (Shea and Jamieson, 2011; Shea et al., 2012b, c) where a thermal camera was used to image the wall in snow pits, which delivers a resolution of less than $2 \mathrm{~mm}$. Shea et al. (2012c) found melt-freeze crusts to be warmer than the surrounding snow. In an hourly measurement setup they presented a warm crust during cooling of the atmosphere. The authors proposed that the warm crust resulted from increased snow internal temperature gradients and water vapour fluxes. They assumed a relatively small ice conduction at the crust which resulted in remnants of undissipated latent heat at the crust. This would indicate that the latent heat transfer is larger than what the conductive ice lattice can handle and thus, warm the grains. In Shea et al. (2012a) they also found relatively cold crusts and related this observation to a reverse 
large-scale snow internal gradient (warmer on top). They assumed that at those times, the crust may have good conduction through the ice matrix (better than adjacent layers), which would cool the grains relative to adjacent layers. However, the explanation of a warm crust based on remnants of undissipated latent heat is contradictory to the finding that the ice matrix is very conductive, likely conductive enough to transport additional latent heat immediately away (Pinzer et al., 2012). Riche and Schneebeli (2013) calculated the ratio between conductive and latent heat flux for thermal conductivity measurements with a heat flux plate during low temperatures $\left(-16^{\circ} \mathrm{C}\right)$. For a temperature gradient of $11 \mathrm{~K} \mathrm{~m}^{-1}$ they calculated the latent heat flux to be less than $1 \%$ of the total measured heat flux. Furthermore, the explanation of a cold crust using the assumption that conductivity characteristics of a crust relative to adjacent layers will reverse with time, dependent on the direction of a large-scale snow internal gradient, seems to be improbable.

Other explanations for the hot-crust/cold-crust phenomenon can be found in the delicate interpretation of the thermal signal. Angular dependencies were found to be important in published literature. Dozier and Warren (1982) theoretically achieved angle dependencies for emissivity values of snow under the assumption of Kirchhoff's law. They concluded that temperature determination errors of up to $3{ }^{\circ} \mathrm{C}$ are expected when the effect of viewing angle is neglected. Viewing angles in a snow pit wall depend on the layering and the porosity. Cutting through a snow pit with a cutting blade or a shovel will produce heterogeneities, especially at crusts. Given the rough porous surface of a snow pit wall and a pixel size of $1 \mathrm{~mm}$ of a thermal image, a wide range of viewing angles may be possible.

Emissivity values are not constant for different snow characteristics. For certain grain sizes and wavelengths $(\sim 12 \mu \mathrm{m})$, the emissivity of snow varies between 0.963 and 0.995 (Dozier and Warren, 1982, Fig. 1). No significant dependencies on density and grain size were found. However, applying these results to small pixel sizes of $1 \mathrm{~mm}$ is questionable, since averaging over non-isotropic grains cannot be assumed at this scale.

Salisbury et al. (1994a) measured emissivity values and compared their results to those theoretically derived by Dozier and Warren (1982), also under the assumption of Kirchhoff's law. Oppositely, they found dependencies on grain size and density: larger particles and denser snow were found to have larger emissivity values. Furthermore, Salisbury et al. (1994b) concluded with laboratory measurements that the assumption of Kirchhoff's law is questionable for extremely low density samples, especially when a thermal gradient is present in the sample. This makes sense, since Kirchhoff's law was derived for isothermal samples at the same temperature as the background to which it radiates (Salisbury et al., 1994b). They used low density quartz powder and applied a thermal gradient to simulate the heating effect of the sun. A highly decreasing density close to the sample's surface was observed (fairy castle structure, see Salisbury et al., 1994b), which resulted in a very low thermal conductivity. They concluded that the heat transfer in the uppermost layer (i.e. the radiating layer or skin layer) is dominated by atmospheric conduction and convection. This uppermost layer was radiating to the cooler laboratory environment and was greatly influenced by air temperature, while this was not the case for the interior of the sample. Thus, a steep gradient developed in the radiating layer. Salisbury et al. (1994b) assumed similar behaviour for snow and the results were later confirmed by Korb et al. (1999) with field experiments. As a result of this steep gradient in the radiating layer, the camera may be able to see either warmer interior or colder exterior sample layers depending on the viewing angle. This was also observed by Shea and Jamieson (2011) on snow surfaces.

Varying emissivity values for different snow types were found with field measurements by Hori et al. (2006). The emissivity for coarse grain snow was found to be 0.927 at $12.5 \mu \mathrm{m}$ for an off-nadir angle of $75^{\circ}$, while for fine dendrite snow at a nadir angle, the emissivity was found to be 0.984 . Hori et al. (2013) explained how these values measured with spectrometers apply to a thermal camera with a broader spectral response. They developed a semi-empirical emissivity model based on measurements which reveal a high reflectivity of crystal facets, while the bulk snow surface shows blackbody behaviour. Using their model Hori et al. (2013) found angular and grain type dependencies in the signal of such a thermal camera. They quantified a possible temperature bias of snow surface temperature measurements assuming clear cold skies and surface temperatures between -5 and $0^{\circ} \mathrm{C}$. For viewing angles smaller than $40^{\circ}$ the temperature bias was found to be less than $-0.8^{\circ} \mathrm{C}$ (excluding bare ice). For larger viewing angles the bias was found to be up to $-3^{\circ} \mathrm{C}$ for coarse grain snow and sun crusts.

Besides emissivity dependencies Shea et al. (2012c) discussed an additional error source. During the assimilation of the exposed snow pit to air temperature, heat may be conducted unevenly from behind, depending on different thermal conductivity properties in certain layers, but they did not find a relevant sharpening of temperature differences (gradients) between pixels over exposure time, which showed them that conductivity differences did not play a major role in interpreting the thermal image.

Our goal with this study was to show systematically, whether a thermal camera was suitable for measuring snow pit-wall temperatures, especially near hard melt-freeze crusts. Since most of the issues cannot be applied directly in a quantitative manner, especially given the small spatial resolution of approximately $1 \mathrm{~mm}$ per pixel, we chose to perform additional field experiments. In Shea et al. (2012b, c) thermal pictures were taken within $90 \mathrm{~s}$ of pit wall exposure. We performed thermal videos while digging and exposing the pit wall, in an attempt to reflect the true internal temperature profile and to gain further insight into how the thermal 
signal changes after exposure. We made observations in the field, and took systematic measurements in a temperaturecontrolled laboratory.

\section{Method}

\subsection{Thermal cameras}

The FLIR B300 and FLIR P660 were used in this study. These cameras are identical to those used in Shea et al. (2012c) and Shea et al. (2012b), respectively. These cameras measure in a spectral range of $7.5 \mu \mathrm{m}$ to $13 \mu \mathrm{m}$. The main differences are the spatial resolution $(320 \times 240$ compared to $640 \times 480$ pixels $)$ and the measurement frequency $(1 \mathrm{~Hz}$ compared to up to $30 \mathrm{~Hz}$ ). The P660 is able to store thermal videos, whereas the B300 requires an external laptop. Different frame rates were chosen $(1 \mathrm{~Hz}, 10 \mathrm{~Hz})$ to address anticipated fast temperature assimilation and possible short time fluctuations due to wind gusts. To be consistent with earlier work, the emissivity was chosen to be 0.98 for the whole image.

\subsection{Snow pits}

Thermal videos were made while digging snow pits. Regular digital videos in the visual spectrum were overlaid with the thermal videos. These videos were helpful to detect crusts, surface structures like shovel scours, as well as to see if dirt or debris was deposited on the pit wall during cutting. The cameras were placed one metre away from a previously dug snow pit. While recording, the snow pit was dug back another $20 \mathrm{~cm}$. The emphasis was speed while creating a smooth snow pit surface with a shovel, a cutting blade or a blunt straight edge of a snow saw. Field work was performed South of Canmore, Alberta, Canada (Kananaskis Country) and at Rogers Pass, British Columbia, Canada. The aim was to capture strong snow internal thermal gradients in shallow snowpacks including crusts during cold and calm weather conditions. Measurements were repeated typically over two hours to address differences in air temperatures, wind speeds and smoothness of the pit wall. The example presented in the Results section was observed at Rogers Pass on 15 December 2012, 6.30 a.m. The air temperature was $-17^{\circ} \mathrm{C}$ during clear sky conditions and calm wind speeds (maximum wind gusts of $1 \mathrm{~m} \mathrm{~s}^{-1}$ measured at nearby weather station) and the snow depth was $80 \mathrm{~cm}$.

\subsection{Cold lab}

In separate experiments, natural snow specimens including a natural crust, laterally isolated boxes with sieved snow, artificial crusts, and artificial snow surfaces of sieved snow were used. All specimens were prepared with artificial concavities (holes) and convexities (bumps). Two examples of snow specimens can be seen in Fig. 1. The scale of the artificial

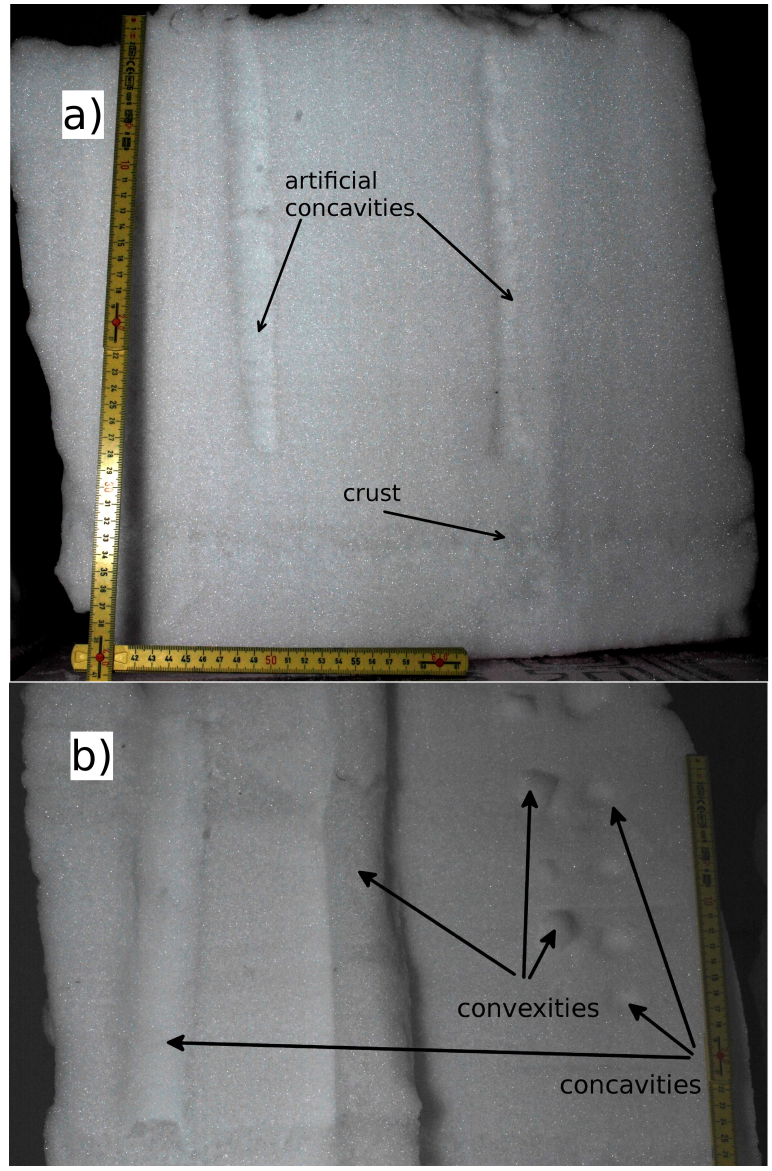

Fig. 1. Specimen with (a) artificial concavities (holes) and a natural crust, and (b) with artificial convexities (bumps) and concavities. Due to the light from the left, the right side of the convexities are dark.

roughness varied from the $1 \mathrm{~cm}$ to $10 \mathrm{~cm}$. The snow specimens were placed outside until isothermal conditions were achieved when the air temperature was approximately $-3^{\circ} \mathrm{C}$. To simulate the sudden exposure of a snow pit, the specimens were placed in the cold lab at approximately $-16^{\circ} \mathrm{C}$. Thermal videos of the snow specimens during the first $10 \mathrm{~min}$ were recorded. Similarly, after isothermal conditions in the cold lab, the specimens were placed outside or in a cooled room at approximately $+3{ }^{\circ} \mathrm{C}$. To achieve a larger control of the conditions, experiments were performed inside the cold lab with changing temperatures. Furthermore, the effect of air flow was tested with fans.

\section{Results}

\subsection{Snow pits}

Cutting through the natural crust produced small concavities even when the aim was to make a planar surface. This can 


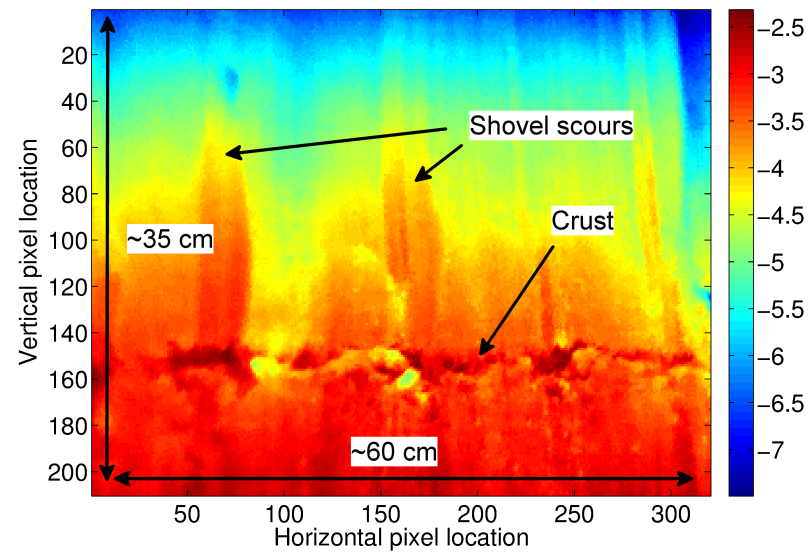

Fig. 2. Thermal picture of a snow pit including a natural crust. Colorbar in ${ }^{\circ} \mathrm{C}$.

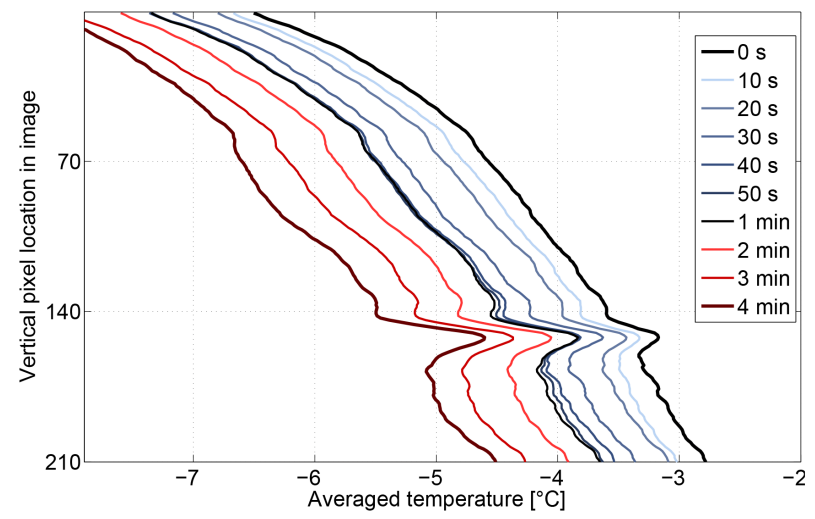

Fig. 3. Mean vertical temperature profiles dependent on time after pit wall exposure. The thick black line represents the situation of Fig. 2.

be explained with the strong bonding between grains forming aggregates, which broke out during the cutting process. Figure 2 shows the first frame after pit wall exposure. This first frame was delayed by a few seconds while the operator smoothed the wall and removed debris laying on the ground which obstructed the pit wall. A melt-freeze crust in the lower part of the image appeared to be relatively warmer than adjacent snow layers. Also visible are shovel scours. The shovel scours were not created intentionally; the aim was to create a smooth pit wall. The depth of the scours are a few millimetres, similarly to the depth of the concavity at the crust. In Fig. 3, mean vertical temperature profiles are plotted for different time steps after pit wall exposure. In the first frame $(0 \mathrm{~s})$, the crust is approximately $0.4^{\circ} \mathrm{C}$ warmer than the layers above. The cooling process after exposure was affected by the clear sky conditions and a large difference between snow $\left(\sim-4^{\circ} \mathrm{C}\right)$ and air temperature $\left(-17^{\circ} \mathrm{C}\right)$. After 1 and $4 \mathrm{~min}$, the pit wall cooled approximately 1 and $2^{\circ} \mathrm{C}$, respectively. The cooling was less pronounced at the crust, which caused the gradient to increase to $0.9^{\circ} \mathrm{C}$ between the

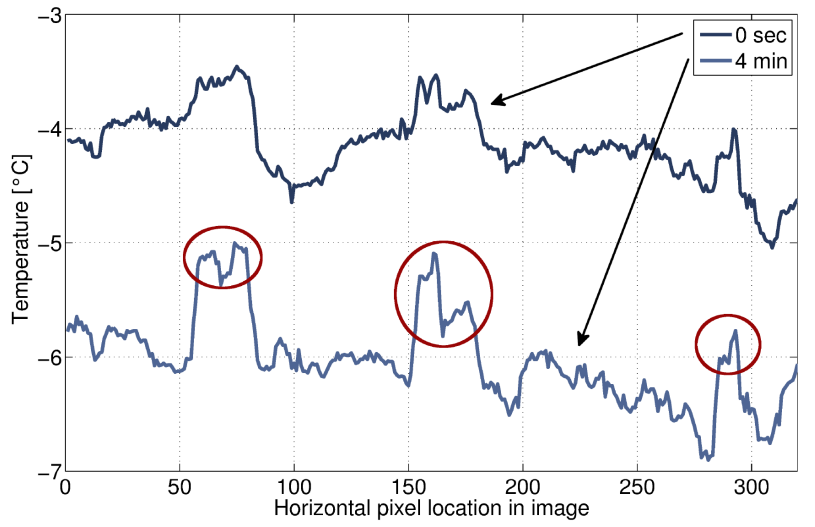

Fig. 4. Horizontal temperature profiles at the first and last time step at vertical pixel location 100 (see Fig. 2). Areas with a slower cooling process are marked in red circles which correspond to the shovel scours.

crust and the layers above after $4 \mathrm{~min}$. Similar effects were observed at the shovel scours. Figure 4 represents a horizontal temperature profile through the shovel scours. Similarly, the initial warm regions did not cool as fast during the general cooling process, resulting in an increased gradient adjacent to these initially warm areas. Overlay photos in the IR and visual range of this and other experiments (not shown) suggest that in sheltered concave areas, the temperature is either warmer or colder compared to flat surfaces, depending whether the air was colder or warmer than the wall of the snow pit.

Shovel scours and sharp edges at the side of a pit wall were not visible in the thermal signal during situations with nearly equal temperatures of snow and air. These findings point to structure dependencies only relevant during temperature assimilation of the pit wall, which was more systematically studied in the cold lab.

\subsection{Cold lab}

Specimens were stored outside overnight during calm and overcast conditions (air temperature $\sim-3{ }^{\circ} \mathrm{C}$ ), after which the specimens were assumed roughly in equilibrium with the surrounding atmosphere. In this condition, both the artificial roughness and the crust were hardly visible in the thermal signal (not shown). Differences between convex and concave areas were smaller than $0.2^{\circ} \mathrm{C}$. This roughness became visible when relatively warm specimens were placed in the cold lab (air temperature $\sim-16^{\circ} \mathrm{C}$ ). Concave areas appeared relatively warm, opposite to convex areas as shown in Fig. 5. The time development of the marked flat, concave and convex areas is shown in Fig. 6. Convex areas cooled faster compared to concave areas, which is consistent with the snow pit observation in the field. After $30 \mathrm{~s}$, the differences between convex and concave areas were larger than one degree. This resulted in an increase in gradients between these areas or 


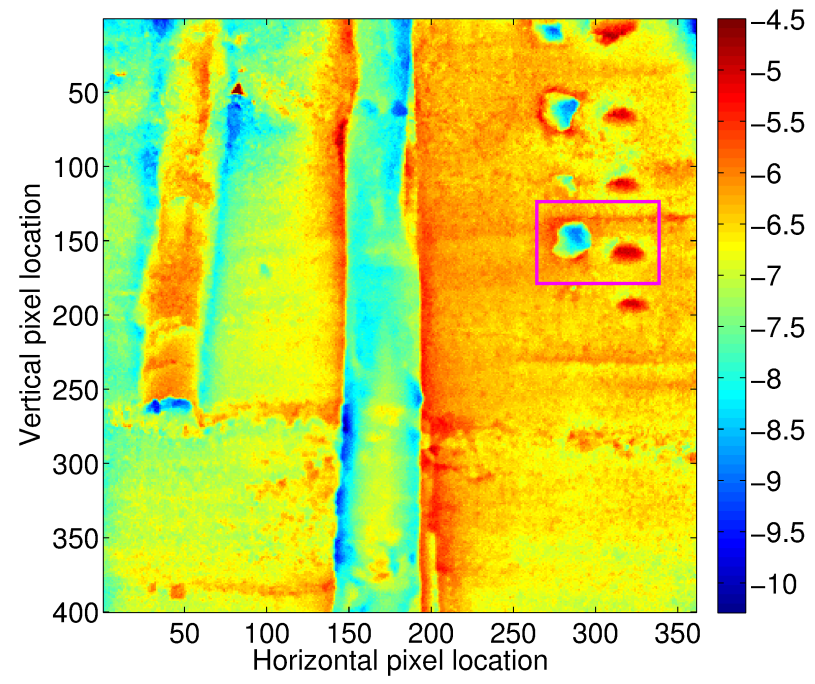

Fig. 5. Thermal image of the specimen shown in Fig. 1b after approximately $4 \mathrm{~min}$ in the cold lab. Artificial concavities are relatively warm, convexities are relatively cold. The marked area is further analysed in Fig. 6. Colorbar in ${ }^{\circ} \mathrm{C}$.

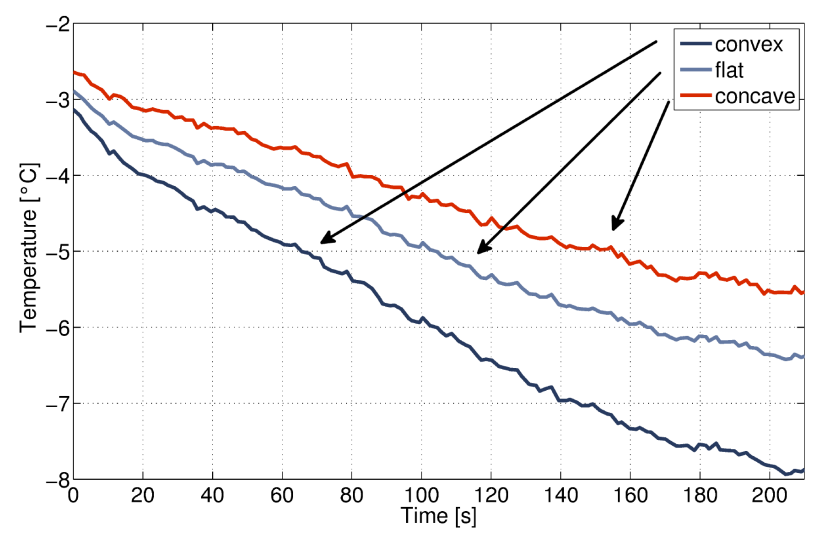

Fig. 6. Time development of the cooling process of the marked areas in Fig. 5.

between pixels. Another specimen with artificial concave areas and a natural crust is shown in Fig. 7a. Both areas appear to be warmer when placed in the cold lab. After a night in the cold lab, these differences were hardly visible in the thermal signal. When the cold specimens were placed outside the cold lab within warmer air temperatures, the opposite was observed. The concave areas and the crust were relatively colder (Fig. 7b), caused by a slower warming process.

This process of different assimilating speed of snow to air temperatures could be observed in the cold lab itself. The cold lab temperature was set to change every $105 \mathrm{~s}$ from warming to cooling. In Fig. 8 it can be seen that convex areas reacted much faster to changing temperatures than concave areas. As a result, gradients between areas and pixels were appearing and disappearing (not shown). The effect of
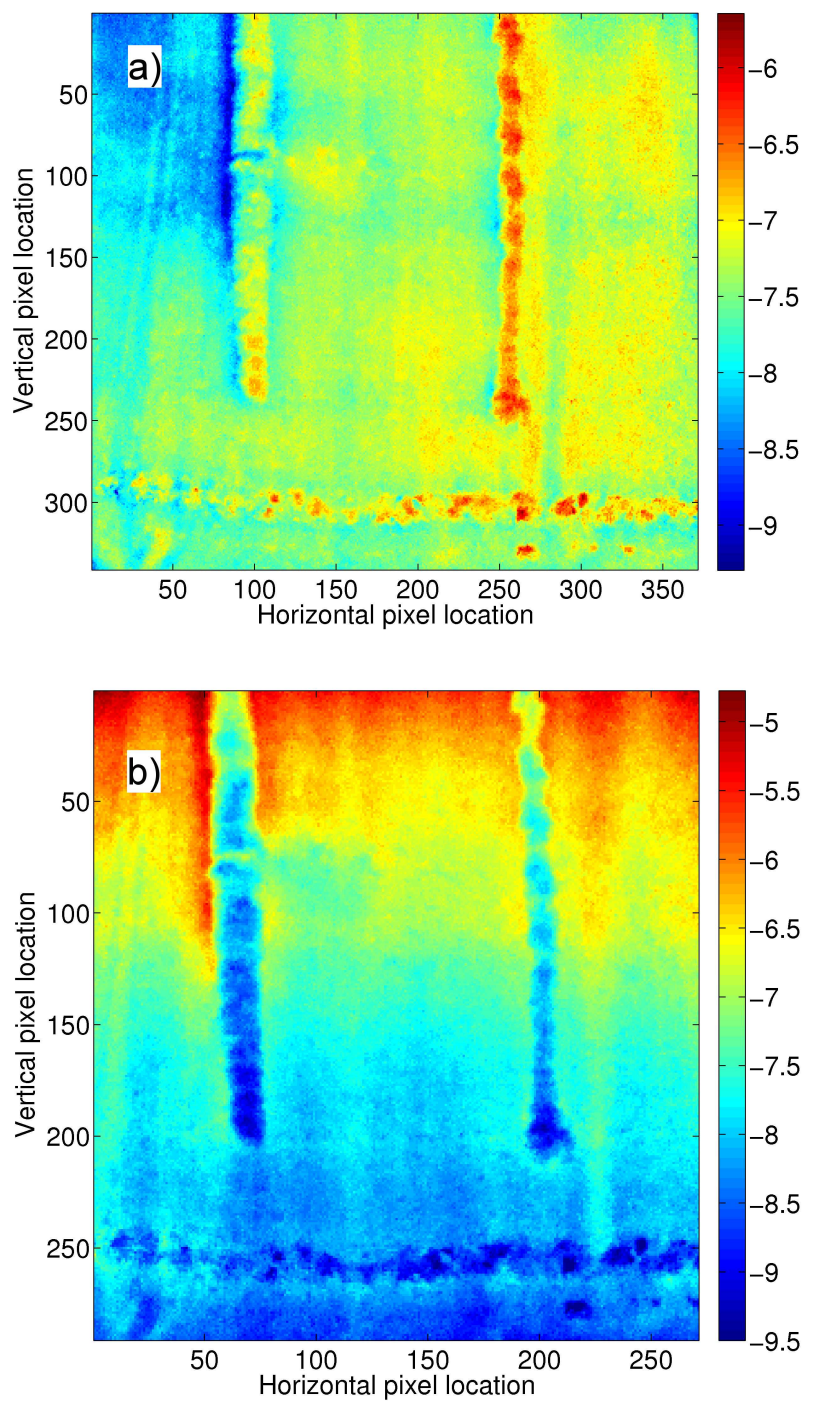

Fig. 7. Thermal images of the specimen shown in Fig. 1a after approximately $4 \mathrm{~min}$, (a) inside and (b) outside the cold lab. Colorbar in ${ }^{\circ} \mathrm{C}$.

air flow (i.e. wind) can be seen in Fig. 9. Large fans in the cold lab produced an air flow from left to right. On the sheltered leeward side of a several centimetre thick convex area $(\sim 5 \mathrm{~cm}$ depth and $\sim 10 \mathrm{~cm}$ width), the snow cooled more slowly and thus resulted in a relatively warm area. This effect is also visible in Fig. 7a, which shows a general gradient from the top left to the bottom right.

\section{Discussion}

The experiments in the cold lab showed differences in the temperatures of a crust or artificial roughness. No internal gradient was applied. Thus, it can be concluded that the thermal image is highly influenced by an energy balance process between snow and air. The larger exposure of convex areas 


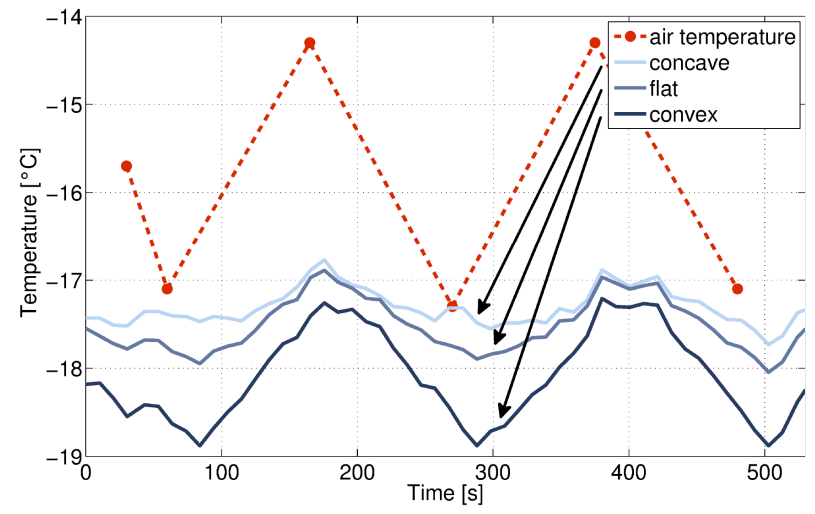

Fig. 8. Snow temperature reacting on changing air temperatures in the cold lab.

compared to flat surfaces and concave areas resulted in faster assimilation of the snow temperatures to air temperatures. This can be explained with a larger radiative process in convex areas. These areas radiate more effectively towards the cold ceiling and walls in the cold lab as compared to concave areas that "see" fractions of relatively warm snow. This effect may be enhanced under cold clear sky conditions in the field. At exposed convex areas, the turbulence intensity of the air flow will be increased. This in turn will increase both sensible and latent heat fluxes (away from the snow pit's or specimen's surface) and therefore contribute to a faster cooling process in the exposed convex areas compared to sheltered concave areas. Furthermore, this explanation is supported by the observation that leeward areas behind artificial convexities were cooling more slowly than windward areas when a directional wind flow was present in the cold lab (Fig. 9). These explanations similarly apply to a slower warming process in concave areas (Fig. 7b).

The act of exposing a melt-freeze crust always resulted in a concavity even when using different cutting instruments with great care. Crusts showed the same surface energy balance process as artificial concavities. However, this does not prove that internal processes in an undisturbed snowpack are not existent to explain a warm crust, as done by Shea et al. (2012c). The initial warm crust shown in Figs. 2 and 3 may suggest such a process. Even though we tried using cutting blades to achieve a first video frame to be closer to the initial exposure of the crust, a relatively warm crust was always present. However, the immediate reaction observed in the cold lab suggests that this could be a result of a surface energy balance rather than an internal process within the snow.

In the Introduction, other explanations were mentioned for a warm crust, i.e. emissivity differences between crusts and adjacent layers or angle differences. There are indications for a crust in a snow pit either to have larger or lower emissivity values compared to adjacent layers. Hori et al. (2013) found microcavities between individual snow particles in a snow surface of melt forms to be warmer than ice particles

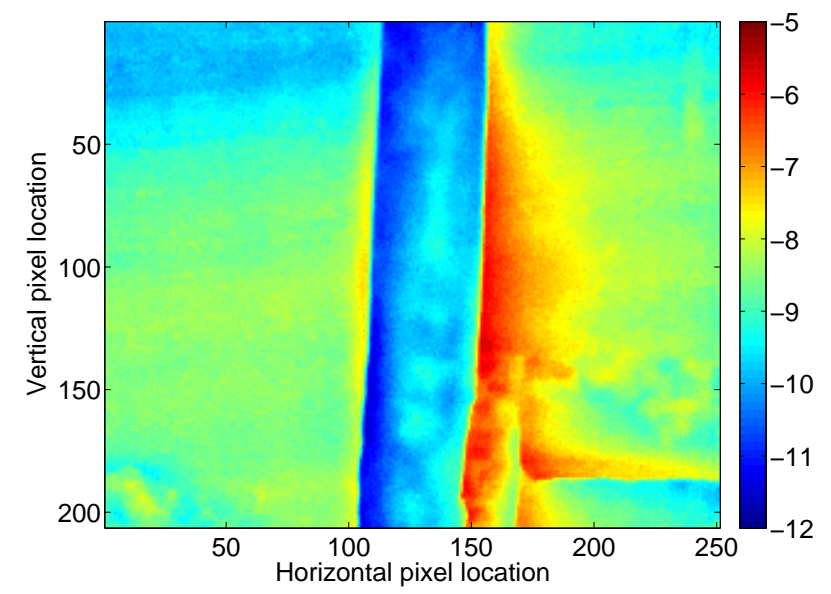

Fig. 9. Effect of cold air flow (from left to right). Relatively warm areas behind a convexity $(\sim 5 \mathrm{~cm}$ depth and $\sim 10 \mathrm{~cm}$ width, similar to a specimen shown in Fig. 1b). Colorbar in ${ }^{\circ} \mathrm{C}$.

on top of the skin surface. Larger radiative cooling may explain the cooler exposed ice particles. With a warm hand over this snow surface Hori et al. (2013) showed that the temperature differences can be explained with emissivity differences between exposed particles and cavities. Exposed ice particles reflected a warm hand, but not cavities. Thus, a crust as a concavity in a snow pit may have a larger emissivity compared to planar areas. On the other hand and as mentioned in the Introduction, coarse grained snow forms have a lower emissivity compared to smaller grain sizes (Hori et al., 2006). We observed only small temperature differences during equilibrium of snow and air. This shows that angular and grain size dependency of emissivity is relatively small in comparison to the surface energy balance process. This impression is consistent with the rather small $\left(<0.8^{\circ} \mathrm{C}\right)$ estimated biases of a thermal camera at viewing angles smaller than $40^{\circ}$ (Hori et al., 2013).

Differences in thermal conductivity properties between a crust and adjacent layers was also mentioned as a potential explanation of a hot crust in the Introduction. Relatively warmer temperatures of snow layers in a freshly exposed snow pit could be caused by a larger conductive heat fluxes in those layers. While creating a warm crust and a warm artificial concavity in the cold lab, we found no obvious differences between crusts and artificial concavities concerning the speed and amount of the process. This similar behaviour in the cold lab supports the argument that both at a crust and at an artificial concavity, the same structure dependent energy balance process plays a dominant role. However, we cannot exclude that the same observations could result from different processes, for example enhanced conduction at a crust and reduced turbulent heat transfer at an artificial concavity. As well, if thermal conductivity properties play a role, this will add more uncertainty in the interpretation of the thermal signal. 
Shea et al. (2012c) found no relevant sharpening of gradients with exposure time. This finding is opposite to what is presented here. During pit wall observations, we occasionally found gradients decreased with time. More regularly, an increase in gradients as shown in Fig. 3 was observed. Under regulated conditions in the cold lab, no exceptions of increasing gradients due to a surface energy process were observed. Shea et al. (2012c) analysed if gradients were forming or disappearing with time after pit wall exposure to address to the effect of different thermal conductivity properties. They argued that an increase in gradients would be a sign that thermal conductivity differences between layers are affecting the thermal images. They analysed 35 pairs of overlapping IR photos captured at different times after exposing the pit wall. They found seven cases in which the median gradient of the overlapping zone decreased with time (larger than pixel sensitivity) and only one significant increase. One explanation for the difference in findings can be found in the relatively long time lapse between snow pit exposure and the first photo taken by Shea et al. (2012c). The largest increases in gradients found in our study were to be in the first 30 to $60 \mathrm{~s}$, both in the cold lab and in the pit walls. No significant differences between single pictures may be observed after $60 \mathrm{~s}$.

Another explanation for the difference in findings is that the overlapping areas used in Shea et al. (2012c) were too large for such a comparison of median values. Large inbetween pixel differences regularly occurred only in thin areas (at the edge of roughness elements) in our study. Typically an increase in a gradient was observed in these thin areas (compare Fig. 4). For the majority of the pixels, in the homogenous parts of the picture, no increase was observed. The small amount of pixels in an overlapping area with an increase in gradients might not have an influence on the median calculation done by Shea et al. (2012c).

In our study we additionally used videos in the visual spectrum and could identify areas with decreasing gradients as snow particles dragged with the shovel or cutting blade to another part of the snow pit (ex situ) during the cutting process. At the beginning, large differences of this ex situ particle resulted in large differences to surrounding pixels and therefore in large gradients. With time, these differences diminished during the general temperature assimilation with the surrounding air. Furthermore, differences in wind intensity have an effect on decreasing or increasing gradients. This was observed both at crusts and shovel scours.

Shea et al. (2012c) found crystal growth to be consistent with measured gradients on a millimetre scale with the IR camera. This is an indication that measured gradients can be related to snow internal process in an undisturbed snowpack. However, this observation could be only an apparent relation: while discontinuous layering may result in discontinuous gradients and thus to crystal growth and faceting, crystal growth and faceting also results in discontinuous cutting surfaces in a pit wall and thus, to differences in the IR signal.
Based on our observations we assume that the warm or cold crusts found in previous studies resulted mostly because of differences in roughness created by cutting through the snow pit. Snow internal processes explaining a hot crust may still be possible, but either to a small or an unknown ratio, since the surface energy process on the pit wall results in large and fast temperature changes. Our explanation of a hot or a cold crust with a surface energy process does not need to assume that a crust is a gap in ice conduction as done in Shea et al. (2012a), which contradicts the picture of a highly conductive ice lattice. Also, it does also not assume that conductivity will be reversed at certain times to explain a relatively cold crust.

\section{Conclusions}

This study investigated the effectiveness of using an IR camera to visualise snow temperatures and small-scale gradients. We tested the camera in both field and lab experiments, focusing on the effect of a non-planar pit wall and wind on the thermal images. Different assimilation speeds with air temperature in concave and convex areas in a pit wall were observed. We explained this effect mainly with a surface energy balance process that can also explain the effect of a formerly observed cold or hot crust in the field. Cutting through a crust with a cutting blade or a shovel produced small concavities even when the aim was to cut a planar surface. This results in a relatively warm or cold crust.

Since it is our opinion that it is not possible to separate snow internal processes from surface energy balance processes using the IR signal, we cannot exclude the existence of snow internal processes to explain a warm crust. Due to our observations of fast and large temperature changes resulting from surface energy balance processes, we can present the limitations of an IR camera to study snow internal processes.

The IR signal is unfortunately unreliable when we are most interested in using its results. For example, at times when large snow internal gradients exist, we anticipate also faster assimilation speeds of the exposed pit wall due to clear sky conditions and large temperature differences between snow and air. We are interested in snow internal gradients near crusts to explain faceting. At these layers, it is likely to obtain a non-planar pit wall due to cutting, which highly influences the thermal signal.

Near surface faceting could be an interesting application for the infrared camera because it appears to be possible to cut a smoother cut in these conditions. A promising picture of a subsurface warming was published in Shea et al. (2012c). Regular thermocouples fail because of the influence of solar radiation. Since the thermal signal is dependent on the structure of the pit wall, it may be used for visualising this structure, and to measure the formation of columnar structure in depth hoar for example. 
Acknowledgements. The authors would like to thank TECTERRA for renting the FLIR P660 and Geoffrey Hay for his cooperation in sharing this camera. For their support of this research we thank the Natural Sciences and Engineering Research Council of Canada, HeliCat Canada, Canadian Avalanche Association, Canadian Avalanche Foundation, Parks Canada, Mike Wiegele Helicopter Skiing, Canada West Ski Areas Association, Backcountry Lodges of BC Association, Association of Canadian Mountain Guides, Teck Mining Company, Canadian Ski Guide Association, Backcountry Access and the BC Ministry of Transportation and Infrastructure Avalanche and Weather Programs. We acknowledge the valuable comments provided by Jeff Dozier and one anonymous reviewer. We are very grateful to the ASARC team at the University of Calgary and Martin Schneebeli for their insightful commentaries on the ongoing work. Many thanks to Alexandra Sinickas, Deanna Andersen and Scott Thumlert for proofreading and to Glacier National Park for the use of their cold lab.

Edited by: F. Dominé

\section{References}

Dozier, J. and Warren, S.: Effect of viewing angle on the infrared brightness temperature of snow, Water Resour. Res., 18, 14241434, 1982.

Hori, M., Aoki, T., Tanikawa, T., Motoyoshi, H., Hachikubo, A., Sugiura, K., Yasunari, T. J., Eide, H., Storvold, R., Nakajima, Y., and Takahashi, F.: In-situ measured spectral directional emissivity of snow and ice in the $8-14 \mu \mathrm{m}$ atmospheric window, Remote Sens. Environ., 100, 486-502, 2006.

Hori, M., Aoki, T., Tanikawa T., Hachikubo, A., Sugiura, K., Kuchiki, K., and Niwano, M.: Modeling angular-dependent spectral emissivity of snow and ice in the thermal infrared atmospheric window, Applied Optics, 52, 30, 7243-7255, 2013.
Jamieson, B.: Formation of refrozen snowpack layers and their role in slab avalanche release, Rev. Geophys., 44, RG2001, doi:10.1029/2005RG000176, 2006.

Korb, A. R., Salisbury, J. W., and D'Aria, D. M.: Thermal-infrared remote sensing and Kirchhoff's law: 2. Field measurements, J. Geophys. Res.-Sol. Ea., 104, 15339-15350, 1999.

Pinzer, B. R., Schneebeli, M., and Kaempfer, T. U.: Vapor flux and recrystallization during dry snow metamorphism under a steady temperature gradient as observed by time-lapse microtomography, The Cryosphere, 6, 1141-1155, doi:10.5194/tc-61141-2012, 2012.

Riche, F. and Schneebeli, M.: Thermal conductivity of snow measured by three independent methods and anisotropy considerations, The Cryosphere, 7, 217-227, doi:10.5194/tc-7-217-2013, 2013.

Salisbury, J. W., D'Aria, D. M., and Wald, A.: Measurements of thermal infrared spectral reflectance of frost, snow, and ice, J. Geophys. Res.-Sol. Ea., 99, 24235-24240, 1994a.

Salisbury, J. W., Wald, A., and D'Aria, D. M.: Thermal-infrared remote sensing and Kirchhoff's law: 1. Laboratory measurements, J. Geophys. Res.-Sol. Ea., 99, 11897-11911, 1994 b.

Shea, C. and Jamieson, B.: Some fundamentals of handheld snow surface thermography, The Cryosphere, 5, 55-66, doi:10.5194/tc-5-55-2011, 2011.

Shea, C., Jamieson, B., and Birkeland, K.: Hot crust, cold crust, Avalanche Review, 30, p. 28, $2012 \mathrm{a}$.

Shea, C., Jamieson, B., and Birkeland, K.: Using a thermal imager to quantify buried thermal structure in natural snow, in: Proceedings of the International Snow Science Workshop 2012, Anchorage, AK, USA, 269-276, 2012b.

Shea, C., Jamieson, B., and Birkeland, K. W.: Use of a thermal imager for snow pit temperatures, The Cryosphere, 6, 287-299, doi:10.5194/tc-6-287-2012, 2012c.

Smith, M. and Jamieson, B.: Tracking changes in buried melt freeze crusts, in: Proceedings of the International Snow Science Workshop 2009, Davos, Switzerland, 107-111, 2009. 